\title{
Problems in the Development of Green Tourism in Henan and Its Countermeasures
}

\author{
Yachang Wang \\ Huanghe Science and Technology College \\ Zhengzhou, China
}

\begin{abstract}
At present, tourism industry has become one of the global largest industries. Due to its rapid development and great success, a lot of regions take the tourism industry as the leading industry or pillar industry in their regional economy. It has been a hot industry. At the same time, the analysis of the impact of tourism on the economy has also become a hot spot in the fields of economics and tourism. Tourism is becoming more and more important in today's society. Tourism can promote regional economic development, improve people's income, and provide more employment opportunities for local residents. Tourism is conducive to expanding the regional economic cooperation and exchanges. Located in the hinterland of the Central Plains, and the middle and lower reaches of the Yellow River, Henan has a long history, splendid culture, magnificent mountains, and rich humanistic and natural tourism resources. In addition, it has a large population, good location and developed traffic. So, it enjoys exceptional advantages to develop tourism. As early as 1990s, the Provincial Party Committee and the Provincial Government have clearly put forward the development strategy of "to pave a way with tourism, to promote a full range of opening up and to prosper Henan's economy". Green tourism can make people long living in the city away from noise and pollution, enable them to get close to the nature and gain a healthy body. Tourism can protect environment and ecological balance, which is a response to the national strategic objective of "taking the road of sustainable development". The richness of the green tourism resources in Henan provides the basis for its development. This paper analyzes the advantages and the main problems in the development of green tourism in Henan, and puts forward some countermeasures.
\end{abstract}

Keywords—green tourism; Henan; sustainable development

\section{INTRODUCTION}

Tourism is a social activity involving economy, environment and culture, which determines the development of tourism is bound to bring a series of positive and negative effects to the economy, environment, society and culture. After the Second World War, tourism industry has made a rapid development around the world, and has become a new sunrise industry. At this time, China's tourism industry also has made a considerable progress.

\section{THE NECESSITY TO DEVELOP GREEN TOURISM IN HENAN}

As a big tourism province in China, the tourism industry of Henan, especially in recent years, has entered a new stage with the development of economy and the upgrading of industrial structure, and its domestic tourism and tourism foreign exchange earnings have been significantly increased. Its domestic tourism and tourism foreign exchange earnings have maintained a growth trend from 1997 to 2009, except that in 2003 it declined because of SARS. And the growth rate is relatively large. In addition, the proportion of the gross income of tourism accounted for GDP and the third industry also showed a gradual upward trend, and it shows a good development trend. But there are also many challenges. For example, tourism products are relatively single, with relatively shallow cultural connotation. The overall level is not high, and quality of service cannot keep up with the actual demand. The publicity work is not enough, and so on. Therefore, the study of Henan's tourism development status and the problems encountered and the ways to solve the problems is of great significance for the future development of Henan's tourism industry and improving the living standards of the people.

Green tourism, as a fashion, not only adheres to the national strategic objective of "taking the road of sustainable development", but also protects environment and the ecological balance. At the same time, it can also make people far away from noise and pollution, get close to the nature, and gain a healthy body.

The proposal of five development ideas, "Innovation, Harmony, Green, Open and Sharing", has pointed out the development path for Henan's tourism industry. Meanwhile, the construction of "Beautiful Henan" requires its tourism to adhere to saving resources, protecting environment and green development in order to form a new pattern of the joint development of human, nature and modern construction. Green tourism makes a beautiful Henan, and also enables Henan to take the road of sustainable development.

\section{The AdVANTAgES to DEVElop GREEN TOURISM IN HENAN}

\section{A. The Rich Green Tourism Resources}

Henan is located in the hinterland of the Central Plains, rich in natural resources. It has a lot of national geoparks, such 
as Songshan Mountain, Funiu Mountain and Wangwu Mountain. Songshan Mountain, Yuntai Mountain in Jiaozuo and Chaya Mountain in Zhumadian are national key scenic spots. There are also twenty-seven national excellent tourism cities, such as Zhengzhou, Luoyang, and Kaifeng. These green tourism resources are not only rich and varied, but also widely distributed. It is a foundation to develop green tourism in Henan.

\section{B. Located In Traffic Thoroughfare}

As China's transportation hub, Henan has a very obvious advantage on railway, highway and aviation. It has 9 trunk railways, such as Jingguang Railway, Jingjiu Railway and Longhai Railway, weaving a large convenient “米”-shaped railway network. There are more than $6000 \mathrm{~km}$ of roads in Henan. It forms a cross-shaped highway network and a highway ring taking Zhengzhou as core. Xinzheng International Airport is Henan's main airport. It has widely distributed airlines and international airlines. It is the gateway of Henan Airlines. Above all, Henan has a convenient transportation.

\section{A Large Number of Consumers}

As of 2015, the population of Henan reached about 107 million, ranking first in China. With the development of urbanization, more and more people begin to explore the connotation of "protecting environment", "returning to nature" and "life". They begin to select green tourism as their main travel mode. The advantage of the large population has laid a solid consumption foundation for the development of green tourism in Henan.

\section{THE PROBLEMS IN THE DEVELOPMENT OF GREEN TOURISM IN HENAN}

Henan has rich resources to develop green tourism, so it has a great potential. But there are still many problems in the development of green tourism.

\section{A. Lack of Publicity and Promotion on Green Tourism}

The large numbers of green scenic spots and consumer groups are the foundation for the development of green tourism. But its publicity and promotion on green tourism are far from enough. Many scenic spots haven't got known by domestic and foreign tourists, and even tourists in Henan know little about their characteristics. The lack of publicity and promotion is the fundamental reason to this phenomenon. At present, Henan only learns publicity of green tourism from advanced provinces, and simply relies on television and internet media. It doesn't combine its own advantages to do the publicity.

\section{B. Lack of the Integration of Tourism Industry Chain}

Henan's green tourism is still in an extensive state. Its tourism products are only at the primary level, and don't show its overall regional value. At present, traditional tourism is still dominated in green tourism. "Visiting temples in the day and sleeping at night" is still the main type of Henan's green tourism. This single type is very unfavorable to the long-term development of green tourism. As for the development of related industries, we are still in the stage of exploration, and don't form an integrated green tourism industry chain.

\section{Shortage of Professional Green Tourism Talents}

Henan has developed lots of scenic areas, nature reserves and other ecological tourist attractions, but we are short of scientific research personnel engaged in environmental monitoring. And only a few scenic spots are able to give environment monitoring. We lack professional talents to develop green tourism. According to statistics, we not only lack development and management talents, but also lack professional service personnel and local community environment professionals. At the same time, we don't carry out wide and long-term education to increase people environmental protection awareness in the tourism. It is very important to improve environmental protection awareness of management personnel of scenic spots and tourists, so that we can truly bring tourists back to nature.

\section{COUNTERMEASURES TO PROMOTE THE DEVELOPMENT OF GREEN TOURISM IN HENAN}

\section{A. To Increase the Publicity and Promotion on Green Tourism}

Henan's green tourism takes the road of sustainable development, which needs to increase the intensity of publicity and promotion on green tourism. We can formulate different strategies aiming at different age stages, different consumer groups and different media. Elderly people prefer TV, newspaper and magazine, so we can use green tourism programs, reports and other ways to promote green tourism. For young people, we can use network to make publicity. Network media are new media, and well received by the majority of young people. Meanwhile, young people are very concerned about tourism and have certain economic foundation. They like drawing near to nature to have a relaxation, so network media are easier to get their attention and attract them to consume on green tourism. The young like to pursue after hot variety shows, and we can combine tourism with entertainment programs to help the young consumers know the green scenic spots of Henan. To invest in film and television is also a good mean for publicity. For example, in If You Are the One, the landscape of Hokkaido was shot poetic and picturesque, which attracts a lot of tourists. In Crouching Tiger and Hidden Dragon, the bamboo forest of southern Sichuan was very magnificent, just like a green sea. These successful cases are good references for Henan to promote green tourism.

\section{B. To Improve the Development of the Marginal Products of Green Tourism}

We need to create a green tourism chain and integrate relevant industries, including food and accommodation, transportation, information, shopping malls and leisure. We should have target in developing marginal products. First, develop green products. As an important link in tourism chain, food and accommodation have been highly concerned, so it is very necessary to deeply develop Henan's characteristic living 
and eating culture. Tourists could enjoy scenery, and meantime learn culture about the Central Plains, so that they can get firsthand experience about Henan. Second, develop and perfect recreational facilities. It enables tourists to experience the fashionable tourist services in scenic spots while appreciating sceneries in the travel. We can establish various recreational facilities, such as bungee jumping in valley, water rafting and bamboo raft, and organically combine local singing with food. We can construct nursing homes in the mountainous area and special theme hotels and rural inns. Tourists can enjoy beautiful sceneries and local culture, and enjoy entertainment in the travel.

\section{To Focus on the Training of Professional Green Tourism Talents}

We can improve the quality of tourism professionals, and regularly impart green tourism knowledge to tourists and tourism service personnel. Meanwhile, we can emphasize the quality of tourism services, and enhance service skills and professional ethics of service personnel. In addition, we can transform traditional tourism education development mode, focus on the training of professional tourism talent, supervise and urge the team construction of administrators, practitioners and badly-needed talents in the scenic spots, and carry out business training to achieve the sustainable development of scenic spots and human resource, and improve the overall level of scenic spots.

\section{To Establish the Scientific Development Ideas}

For the development of Henan's economy, it is necessary to take tourism as a new economic growth point. It should be noted that, for some countries and regions with mature tourism, tourism is a sunrise industry with small investment and large output. But, in view of our actual situation, our tourism industry is still in an initial stage, with large investment and slow development. We don't possess the development characteristics of a mature tourism industry. Therefore, it is necessary to establish the scientific development ideas.

First of all, we need to do a good job in tourism development planning. In the actual construction, we should avoid flatulent vanity projects and earnestly make short-term and long-term planning. Secondly, we should highlight the focus of development. Henan has many tourism resources but limited capital investment, so we should avoid the idea of complete-coverage development. We can use our limited economic power on special economic spots and excellent routes, and focus on key projects and construct these key projects batch by batch, so as to form a trend of development from a point to an area, and give full play to the radiation and drive role of characteristic tourist routes and major tourist attractions. Thirdly, we should build a large platform for tourism development. To develop tourism, we should be far sighted and not limited to the current ticket economy, regard the whole local economy as a system, and establish a reasonable balance system to facilitate the organic cooperation of tourist sectors, commonly prosper Henan's tourism, and achieve a sustainable development and win-win situation. Finally, we can mine social resources and use various management methods. In some hot tourism areas, we should especially give full play to the enthusiasm of local residents, construct family inns, and integrate self-residence and operation together. By this way, we can relieve the pressure of over consumption demand in busy season, reduce lose of resources, like starred hotels, in slack season, provide more opportunities for local people to gain wealth, and provide tourists more opportunities to closely contact local people and experience local folk culture.

\section{CONCLUSION}

The development of tourism industry in Henan has created a large number of employment opportunities for Henan people, optimized and upgraded the industrial structure of Henan, promoted, improved and enhanced Henan's infrastructure construction, driven the development of urban and rural areas, and speeded up the pace of building a harmonious society.

However, there are several problems: single tourism products, weak market competitiveness, the lack of scientific planning and guidance, low overall development level of tourism resources, hysteretic tourist service, defective tourism management system, unsound management, and unreasonable and imperfect tourism industrial structure.

The development strategy of Henan's tourism industry is to take the road of big tourism province, sustainable development and government leading. The implementation of big tourism province is to stimulate domestic demand, increase employment and promote social harmony. Considering our provincial situation and the development of economy and society, the tourism industry in Henan should be coordinated with the resources and the environment in the long run, and take the road of sustainable development and government leading, so as to give full play the social function of tourism and optimize the allocation of resources.

In order to make the tourism industry of Henan healthy and stable, we should do the following: first, establish a new image of Henan tourism and improve our tourism environment. Second, vigorously develop the tourism-related industries, cultivate a large tourism industry system, and do a good job in the development of tourism products. Third, actively carry out relevant education and cultivate excellent employees. Fourth, use scientific management methods to improve the operating order. Fifth, strengthen study and continuously update the business philosophies according to the development situation of the industry.

Green tourism is a booming sunrise industry. With the increase of people's income and improvement of life quality, the demand for green tourism in the market is also growing. Henan has rich tourism resources. But we should help our people establish a green consciousness, deeply develop and vigorously promote tourism products, perfect and integrate the entire green tourism chain to achieve the real benign sustainable development of the green tourism in Henan.

\section{REFERENCES}

[1] Wang Caini. Domestic and Foreign Green Tourism Research Progress. Journal of Henan Business College. 2015. 
[2] Zhang Xiaohua. Economic Analysis on Green Tourism Economy. Modern Business. 2014.

[3] Bao Xiaoguang. Innovative Research on Marketing Strategy of Green Tourism in Henan. Journal of Jiaozuo University. 2010.

[4] Wei Min. Study on Green Tourism Development Model Based on the Perspective of Low-carbon Economy. Economic Management. 2011.

[5] Fang Fang. Discussion on Green Tourism Economy. China Science and Technology Expo. 2015.. 